\title{
Evaluations of CTOD and J-integral for Three- point Bend Specimens with Shallow Cracks
}

SHANG-XIAN WU

Department of Mechanical Engineering, University of Sydney, NSW 2006, Australia

\section{ABSTRACT}

Analytical predictions and experimental determinations of near-field and far-field Whictic rotpion factors and J-integral estimation formula for three-point specimens plastic rotationd and ou with a free-cutting steel show that the initiation fracture toughness $\left(\delta_{i}\right.$ and $\left.J_{1 c}\right)$ are than for deep cracks by a factor of approximately 2.3 and 2.7 higher for shall
respectively.

\section{KEYWORD}

Elastic-plastic fracture test, shallow crack, rotation factor, crack tip opening lisplacement, J-integral

\section{INTRODUCTION}

Most standard elastic-plastic fracture toughness test methods recommend the use of deeply-cracked specimens. Fracture toughness data are therefore mainly obtained on unch specimens. However, in structures, particularly welded ones, many defects are in the form of shallow cracks. Recent results (Chipperfield, 1978; Cotterell et al., 1985; Matsoukas, et al., 1986a, Thompson and Knott, 1986; Towers and Garwood, 1986) show that the elastic-plastic fracture toughness values at initiation of crack grow $\left(\delta_{1}\right.$ or $\left.{ }_{10}\right)$ (he deep cracks. Consequently the assessment of the are higher for shallow ingnificance of a practical shalled specimens can be unduly conservative. There standard test with deeply the aim o increasing interest in fraction paper is to better understanding three point bend specimens with shallow cracks.

\section{CALCULATIONS OF CTOD AND J-INTEGRAL}

Plastic Rotation Factors ( $r_{D}$

In standard methods the crack tip opening displacement (CTOD), $\delta$, is obtained from 
the sum of elastic component $\left(\delta_{\mathrm{e}}\right)$ and plastic component $\left(\delta_{\mathrm{P}}\right)$. $\quad \delta_{\mathrm{e}}$ is calculated from the the sum of elastic component $\left(\delta_{\mathrm{e}}\right)$ and plastic compoplied load and $\delta_{\mathrm{p}}$ is calculated from nominal stress-intensity facement $\mathrm{V}_{\mathrm{p}}$ according to the the plastic conse specimen rotate about a plastic hic corint in the uncracked ligament. The distance of the plastic hinge point flast the crack tip is $r_{p}(\mathrm{~W}-\mathrm{a})$, where $\mathrm{W}$ is the specimen width, $a$ is the crack length and fron the plastic rotation factor. A problem of CTOD test of shallow crack specimens is $r_{p}$ is the plasticion of the plastic rotation factor $r_{p}$. There are two definitions of $r_{p}$ : the far-field and the near-field definitions. The far-field plastic rotation factor ifp is defined by use of displacements far from the crack tip such as the crack mouth opening displacement $V_{p}$ and the load-point displacement $q_{p}$ according to the plastic hinge deformation model. The plastic rotation factor determined by the and Garwood, 1986 ; clip-gauge method (Lin et al., 1982; Matsoukas et al., , $\mathrm{Wu}, 1983)$ is $\mathrm{r}_{\mathrm{fp}}$. The near-field plastic rotation factor $\mathrm{r}_{\mathrm{np}}$ is calculated the stretched and the near-field measurement of $\delta_{\mathrm{p}}$ obtaine that the crack surfaces to remain straight. Hence

$$
\mathrm{r}_{\mathrm{np}}=\frac{\mathrm{a}+\mathrm{z}}{\mathrm{W}-\mathrm{a}} \frac{\delta_{\mathrm{p}}}{\nabla_{\mathrm{p}}-\delta_{\mathrm{p}}}
$$

The slip-line field in Fig. 1 shows that the where $\mathrm{z}$ is the thickness of the kne point bend specimen follows the

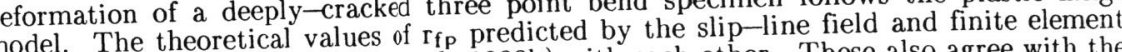
analyses are in agreement (Wu tt al., 1988b) with each other. These also agree with the experimental values of $\mathrm{r}_{\mathrm{f}} \mathrm{p}$ and $\mathrm{Inp}_{\mathrm{p}}$ (Lin et al., 1982, Malip-line field analyses (Wu et al For specimens with shallow cracks (a/ $\leq 0.172$ ) the slip- within the rigid zone KGCVT 1988a) show that the crack face and the crack ligament with angular velocity wh The (Fig. 2), which rotates about the uncracked

pecimen arms rotate with angular velocity $\omega_{1}$

$$
\frac{\omega_{1}}{\omega_{2}}=1.747-6.829 \stackrel{\mathrm{a}}{\mathrm{W}}+14.74\left[\frac{\mathrm{a}}{\mathrm{W}}\right]^{2}, \quad \text { for } \stackrel{\mathrm{a}}{\mathrm{W}} \leq 0.172
$$

a $/ \mathrm{W}>0.172, \omega_{1} / \omega_{2}=1$. If the plastic deformation is small as in the case of the For a/W $>0.172, \omega_{1} / \omega_{2}=1$. If thetry gives

$$
r_{f P}=W-a \frac{\omega_{1}}{\omega_{2}} \frac{V_{p}}{q_{p}}-\frac{a+z}{W-a}
$$

Fig. 3 shows the $r_{f}$ values predicted by slip-line field analyses for perfectly plastic Fig. 3 sho (solid line) and by use of the finite element data of Kumar et al. (1981) for mawer-law hardening materials $(\mathrm{n}=2$ to 20 ). Since the deformation of crack tip involves

blunting and finite strain, there is no available analytical result of $\mathrm{r}_{\mathrm{n}}$

\section{J-integral Estimation Formula}

In ASTM E813 $\mathrm{J}$-integral is estimated by

$$
\mathrm{J}=\mathrm{J}_{\mathrm{e}}+\mathrm{J}_{\mathrm{P}}=\frac{\mathrm{K}^{2}}{\mathrm{E}^{\mathrm{T}}}+\frac{\eta_{\mathrm{p}}}{\mathrm{B}(\mathrm{W}-\mathrm{A}}
$$

where $A_{p}$ is the plastic part of the area under the load vs load-point displacement curve. $\eta_{\mathrm{p}}$, the plastic $\eta$-factor, is taken as 2 for deeply cracked three-point bend limit load $P$ of the specimen according to

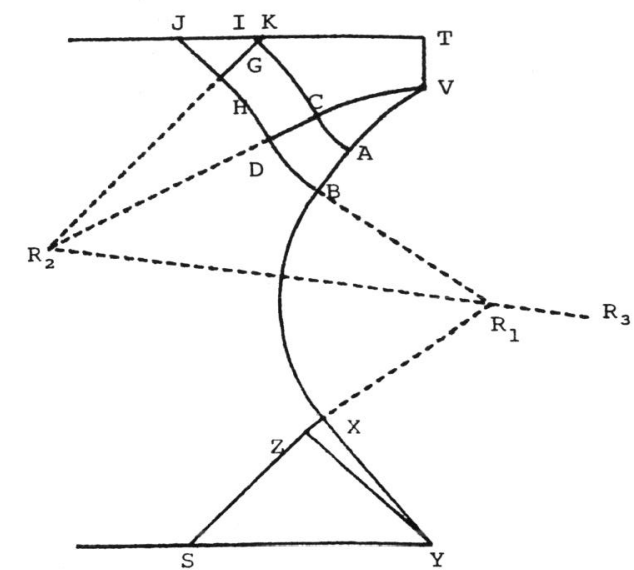

Fig. 2 Slip-line field of threepoint bend specimen with shallow crack.

Fig. 1 Slip-line field of three-point bend specimen with deep crack.

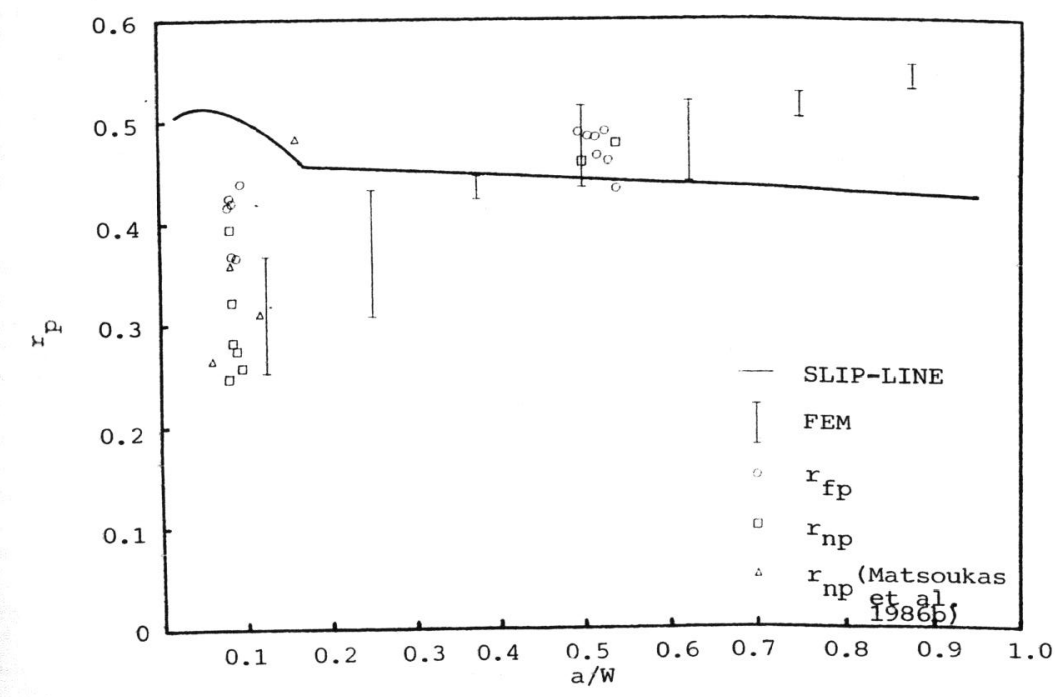

Fig. 3 Comparisons of analytical predictions of $r_{f p}$ and experimental results of $r_{f p}$ and $r_{n p}$. 


$$
\eta_{\mathrm{P}}=-\left(1-\frac{\mathrm{a}}{\mathrm{W}}\right) \frac{1}{\mathrm{P}_{\mathrm{L}}} \frac{\partial \mathrm{P}_{\mathrm{L}}}{\partial(\mathrm{a} / \mathrm{W})}
$$

Towers and Garwood (1986) and Sumpter (1987) used $\eta_{\mathrm{P}}$-factor obtained from the limit load of pure bending specimens to $\mathrm{J}_{\text {IC }}$ tests of three point bend specimens. Thi procedure is clearly incorrect. It is possible to obtain theoretical slip-line field solutions procedure is clearly incorrect. It is possive
of three point bend specimens which give

$$
\mathrm{P}_{\mathrm{L}}=\left[1.125+0.892 \frac{\mathrm{a}}{\mathrm{W}}-2.238\left(\frac{\mathrm{a}}{\mathrm{W}}\right)^{2}\right] \frac{2}{\sqrt{3}} \frac{(\mathrm{W}-\mathrm{a})^{2}}{\mathrm{~S}} \mathrm{~B} \sigma_{\mathrm{ys}}
$$

for $\stackrel{\mathrm{a}}{\mathrm{W}} \leq 0.172 . \mathrm{S}$ is the span, $\mathrm{B}$ is the specimen thickness and $\sigma_{\mathrm{ys}}$ is the yield strength of the material. Hence

$$
\eta_{\mathrm{p}}=2-\frac{(1-\mathrm{a} / \mathrm{W})(0.892-4.476 \mathrm{a} / \mathrm{W})}{1.125+0.892 \mathrm{a} / \mathrm{W}-2.238(\mathrm{a} / \mathrm{W})^{2}},
$$

for $\mathrm{a} / \mathrm{W} \leq 0.172$

\section{MATERIALS AND EXPERIMENTAL PROCEDURES}

The test material was a free-cutting steel in normalized condition with the composition: $0.060 \mathrm{C}, 1.16 \mathrm{Mn}, 0.29 \mathrm{~S}, 0.075 \mathrm{Si}, 0.066 \mathrm{P}, 0.018 \mathrm{Ni}, 0.012 \mathrm{Cr}, 0.002 \mathrm{Mo}, 0.016 \mathrm{Cu}$, $0.002 \mathrm{~V}$ and $0.002 \mathrm{~N}$. The mechanical properties were: yield strength $\sigma_{\mathrm{ys}}=202 \mathrm{MPa}$,

ultimate tensile strength $\sigma_{\mathrm{ts}}=338 \mathrm{MPa}$, elongation $=29.3 \%$ and reduction of area ultimate tensile strength $\sigma_{\mathrm{ts}}=338 \mathrm{MPa}$, elongation $=29.3 \%$ and thedentength and
$=34.9 \%$. Specimens of $\mathrm{B}=14 \mathrm{~mm}, \mathrm{~W}=25 \mathrm{~mm}$ were machined so that the length ans width dimensions lay in a plane normal to front. Two crack length ratios a $/ \mathrm{W}=0.5$ inclusions we the and a/W $=0.1$ width to $\mathrm{W}=22.5 \mathrm{~mm}$ to produce the desired a/W specinen air of int ratio. A pair of integrated the distance between the knife-edges was $5 \mathrm{~mm}$ and the knife-edges were within the rigid zones.

Tests were performed in three-point bending using an Instron 1195 testing machine at a Tor clip gauges were used, one for crack mouth opening displacement $(V$, another for load-point displacement (q). For each specimen $\mathrm{P}-\mathrm{V}$ and $\mathrm{q}-\mathrm{V}$ records were taken on an $\mathrm{X}-\mathrm{Y}-\mathrm{Y}$ chart recorder and $\mathrm{P}-\mathrm{q}$ record was taken on a second $X-Y$ recorder. Individual specimens were unloaded from different positions along the $\mathrm{P}-\mathrm{V}$ curves to obtain different amount of crack growth $\Delta \mathrm{a}$. All unloaded shallow crack specimens and two unloaded deeply-cracked specinens sectioned at distances of $1 / 6,1 / 3$ and $1 / 2$ thickness from one free surface of the specimen. The sections of shallow crack specimens we po the three sections Near-field measurements of $\delta_{\mathrm{p}}$ at the original crack tip were made on the three sections and an average was obtained for each specinen. specimen were aged at $250^{\circ} \mathrm{C}$ or 30 minutes and then w mark was made at the upper Fry's reagent to reveal the plastic deformation bands. A mark was made at the upper boundaries of the deformation bands as shown in mark the remained repolished and near-field measurements op at unsectioned parts of the specmens were hecimens were directly liquid nitrogen temperature. Other unloaded deeply-cracked specimens ack length and heat-tinted and broke meerem from the broken surfaces and the sections.

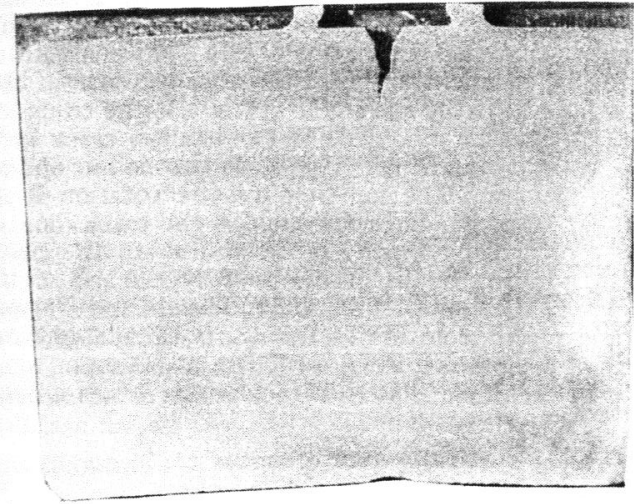

Fig. 4. Fry's etched section of Fig. 5. Fry's eched section of shallow crack specimen.

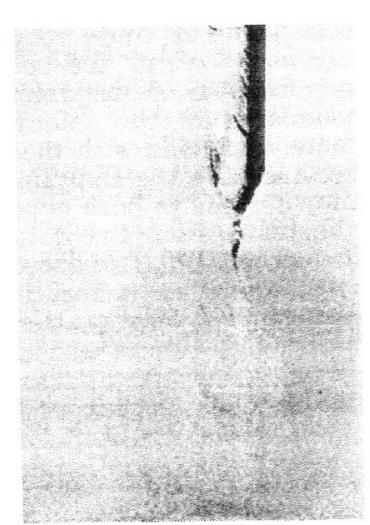

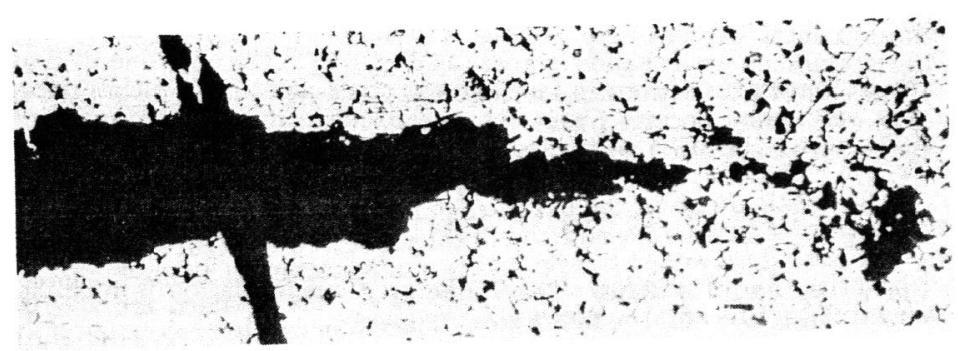

F. Micrograph of crack tip of deep crack specimen showing the crack tip and the mark.

RESULTS AND DISCUSSION

\section{Plastic rotation factors}

Values of $r_{f p}$ were calculated using Eq. (3). The $\left(V_{p} / q_{p}\right)$ ratios were taken as the slopes $f$ the $\mathrm{V}$ q records after general yielding of the specimen. The experimental records how that after traightlines. Therefore the slopes of the $\mathrm{V}-\mathrm{q}$ lines represent the ratio of $\Delta V_{p}$ and $\Delta q_{p}$ The experimental results of $r_{f p}$ are also given in Fig. 3 alongside the theoretical predictions. Values of $\mathrm{r}_{\mathrm{np}}$ were calculated using $\mathrm{Eq}$. (1) with the near-field predictions. previously by Matsoukas et al. [1986b] are also represented in Fig. 3. 
It can be seen that for deeply-cracked specimens the predictions of $r_{f p}$ given by slip-line field and finite element analyses and the experimental values of $r_{f p}$ and $r_{n p}$ are in good agreement. In practical specimens the idealized isolated slip-lines in Fig. 1 become deformation bands of finite width. Observations show that the width of deformation bands increases towards the bottom free surface of the specimen as the deformation increases. Becaus of the deformation bands, i.e. the boundaries of the rigid zones, upper boundaries of the with the tip of the precrack. Therefore $r_{f p}$ and $r_{n p}$ agree with approximately with the analytical predictions. For shallow crack specimens the plastic deformation spreads to both upper and bottom surfaces. Thickening of the deformation bands is therefore along two directions (i.e. towards both upper and lower surfaces) and the rigid zone KGCVT is reduced. This makes accurate measurements of $V_{p}$ extremely difficult and consequently makes the calculations of $r_{f p}$ and $r_{n p}$ using Eqs. (1) and (3) highly suspect. The large scatter of $r_{p}$ shown in Fig. 3 supports this conclusion. There is also some discrepancy between the $r_{f} p$ predictions given by the slip-line field and finite element analyses. Similar experimental results of $\mathrm{r}_{\mathrm{fp}}$ are obtained by Sumpter (1987) who did not take account for the factor $\omega 1 / \omega_{2}$. You (1984) gave the experimental values of $r_{n p}=0.2$ and 0.15 for four-point bend specimens with $\mathrm{a} / \mathrm{W}=0.2$ and 0.1 respectively. But the equation for calculation of $r_{n p}$ used by You

$$
\mathrm{r}_{\mathbf{n} \mathbf{p}}=\frac{\mathrm{a}+\mathrm{z}}{\mathrm{W}-\mathrm{a}} \frac{\mathrm{V}_{\mathrm{p}}}{\delta_{\mathrm{p}}}
$$

is incorrect. With the correct equation (1) much higher $r_{n p}$ values would have been is incorrect. With the correct equation obtained from You's data. All these problems prack specimens.

\section{$\underline{\text { CTOD Test }}$}

$\mathrm{P}-\mathrm{V}$ records and etched sections show that fibrous crack growths for both deep and

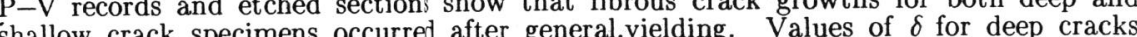
were calculated using the BS 5762 procedures except with $r_{p}=0.45$ as suggested in our earlier work. For shallow cracks $\delta_{\mathrm{p}}$ were measured from three cut sections across the thickness. $\delta_{\mathrm{e}}$ were calculated in the usual way and added to $\delta_{\mathrm{p}}$ to give the total $\delta$. Fig. 4 shows the data of $\delta$ versus $\Delta \mathrm{a}$ and the linear regression $\delta-\mathrm{R}$ curves. Values of $\delta_{\mathrm{i}}$ at crack initiation were determined by the points of intersection of the $\delta$-R curves and the theoretical blunting line $\delta=2 \Delta \mathrm{a}$. The values of $\delta_{\mathrm{i}}$ thus obtained are $\delta_{\mathrm{i}}(\mathrm{a} / \mathrm{W}=0.5$ $=0.082 \mathrm{~mm}$ and $\delta_{\mathrm{i}}(\mathrm{a} / \mathrm{W}=0.1)=0.192 \mathrm{~mm}$. Therefore, for the test material, the effec of reducing a/W from 0.5 to 0.1 is to increase $\delta_{i}$ by a factor of 2.3 . This effect is related to the reduction of stress-triaxility ahead of the shallow crack tip due to the plastic deformation spreading to both specimen surfaces. The slip-line field analyses show that 0.5 to $2.37 \mathrm{k}$ for $\mathrm{a} / \mathrm{W}=0.1$, whee $\mathrm{k}$ is the shear yield stress of the material.

\section{J-integral Test}

Values of J-integral for deeply-cracked specimens were calculated using ASTM E813 procedures. Values of J for shallow crack specimens were calculated using Eqs. (4) and (7) but were qualified using ASTM-E 13 procedures. The J were determined from the regression $\mathrm{J}-\mathrm{R}$ curves are plotted points of intersection of the $\mathrm{J}-\mathrm{R}$ curves and the blunting line $\mathrm{J}=2 \sigma_{\mathrm{y}} \Delta \mathrm{a}$, where $\sigma_{\mathrm{y}}$ is
the average of $\sigma_{\mathrm{ys}}$ and $\sigma_{\mathrm{ts}}$. The test results show that $\mathrm{J}$ increases from $30.3 \mathrm{kJm}^{-2}$ for $\mathrm{a} / \mathrm{W}=0.5$ to $81.0 \mathrm{kJm}^{-2}$ for $\mathrm{a} / \mathrm{W}=0.1$ by a factor of 2.7 .

It seems that the shallow crack data in Fig. 8, if fitted to a curve, might agree with the dhe inclusion of the rejected data point $\left(\Delta \mathrm{a}=0.18 \mathrm{~mm}, \mathrm{~J}=58.8 \mathrm{kJm}^{-2}\right)$ just outside the $0.15 \mathrm{~mm}$ exclusion line into $\mathrm{J}-\mathrm{R}$ curve regression would give $\mathrm{J}_{\mathrm{Ic}}=64.0 \mathrm{~kJ} \mathrm{~m}^{-2}$ for the shallow crack. On the other hand the interpretation of the qualified data in terms of the procedure of power curve fitting and $0.2 \mathrm{~mm}$ offset line give $\mathrm{J}_{\mathrm{Ic}}(\mathrm{a} / \mathrm{W}=0.5)=44.6 \mathrm{~kJ} \mathrm{~m}^{-2}$ and $\mathrm{J}_{\mathrm{IC}}(\mathrm{a} / \mathrm{W}=0.1)=76.9 \mathrm{~kJ}$ $\mathrm{m}^{-2}$ respectively. Therefore, it can be concluded that the effect of a/W is not due to the $\mathrm{m}^{-2}$ respectively. Therefore,
uncertainty of interpretation.

\section{CONCLUSIONS}

Analytical predictions and methods for experimental determination of near-field and far-field plastic rotation factors of three-point bend specimens are presented. The lar-fimental $r_{n p}$ and $r_{f p}$ are the same for deeply-racked specimens, but are difficult to measure accurately for shallow crack deeply from $\mathrm{a} / \mathrm{W}=0.5$ to $\mathrm{a} / \mathrm{W}=0.1$ on the teciment in terms of $\delta$ test material are that the fracture toughness a increases by a factor 2.3 and 2.7 respectively. These effects are related to the reduction of the stress-triaxility ahead the crack tip as the crack length is reduced.

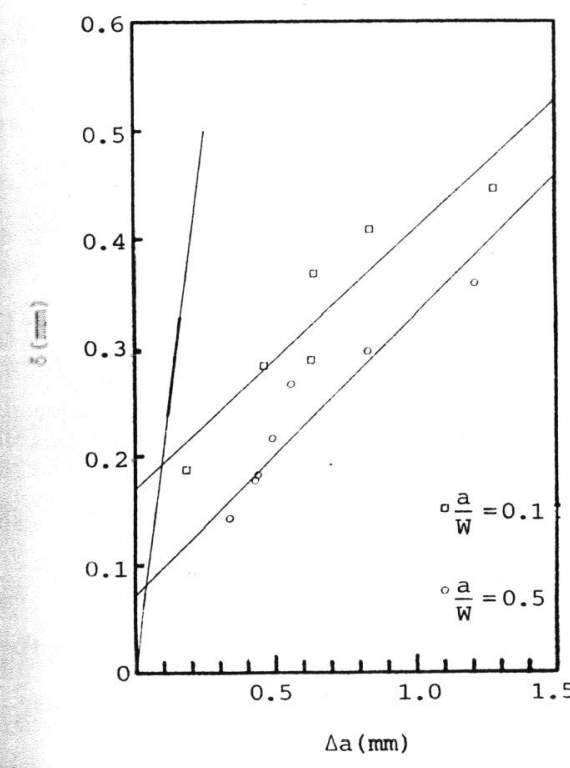
$\begin{array}{ll}\text { Fig. } 7 & \delta \text {-R curves for deep and } \\ \text { shallow crack specimens. }\end{array}$

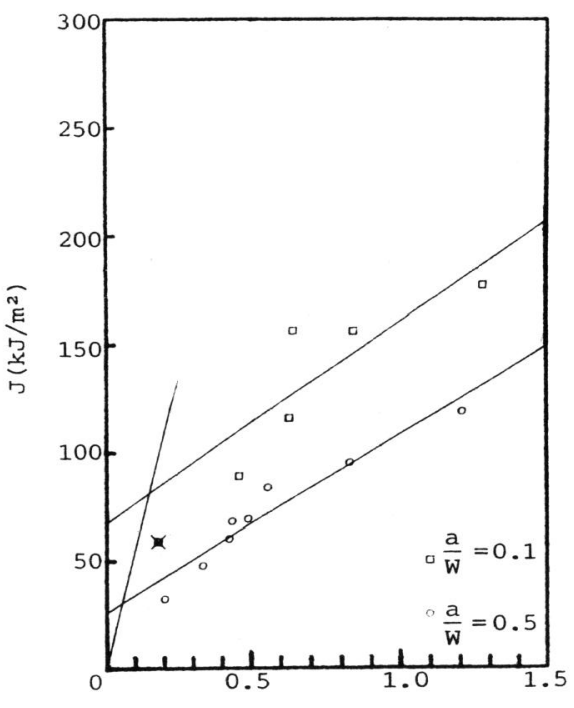

$\Delta \mathrm{a}(\mathrm{mm})$
Fig. 8 J-R curves for deep and shallow crack specimens. represents the rejecte data. 


\section{Acknowledgement}

I wish to thank the University of Sydney for a Postgraduate Research Award and the Australian Welding Research Association for the Sir William Hudson Memorial Award. I wish also to thank Professor Y-W. Mai and Dr. B. Cotterell for useful discussion on this work

\section{REFERENCES}

ASTM E813-83. Standard test for $\mathrm{J}_{\text {Ic }}$, a measure of fracture toughness.

BS 5762 (1979). British Standard, Method for crack opening displacemen (COD) testing. (1978). Some observations on ductile crack initiation an 作 Elastic-Plastic Fracture Mechanics, Vol. 2, OECD Nuclear Energy Agency Daresburg, Paper 15.

Cotterell, B., Q.-F. Li, D.-Z. Zhang and Y.-W. Mai (1985). On the effect of plastic constraint on ductile tearing in a structural steel. Engng Fract. Mech., 21 $239-244$.

Lin, I.H., T.L. Anderson, R. De Witt and M.G. Dawes (1982). Displacements and rotational factors in single edge notched bend specimens. Int. J. Fracture, 20 R1-7.

Kumar, V., M.D. German and C.F. Shih (1981). An engineering aproach for lastic-plastic fracture analysis, Topical Report No. EPRI-NP-1931, Research (1984). N.Y.

, On the plastic rotation constant used in standard COD tests. Int. J. Fracture, 26, R49-53.

Matsoukas Ged in stantard ond Y.-W. Mai (1986a). The effect of shallow cracks on crack tip opening displacement. Engng. Fract. Mech., 24, 837-842.

cracks on crack tip opening displa $\mathrm{Y}-\mathrm{W}$. Mai (1986b). Hydrostatic stress and 政 Mech. Phys. Solids, 34, 499-510.

J J determination for shallow notch welded bend specimens. Fatigue Fract. Engng. Mater. Struct., 10, 479-493.

Thompson, H.E. and J.F. Knott, (1986). Effects of crack length and prestrain on ductile fracture. Fracture Control of Engineering Structures, ECF-6.

Towers, O.L. and S.J. Garwood (1986). Influence of crack depth on resistance curves for three-point bend specimens in HY130. Fracture Mechanics: Seventeenth Volume, ASTM STP 905, 451-484.

Wu, S.-X. (1983). Plastic rotational factor and J-COD relationship of S. - pint bend specimen. Engng Fract. Mech., 18, 83-95

Wu, S. -X., B Cotterell and Y.-W. Mai (1988a). Slip-line field solutions for three-point notched-bend specimens. Int. J. Fracture, (in press).

(1988b) Plastic rotation factors of Journal of Testing and (in press)

You, C.P. (1984). Mecharisms of fracture in high strength steels. PhD Thesis, University of Cambridge. 